\title{
Synthesis of titania/carbon nanocomposites by polymeric precursor method
}

\author{
Neftali L.V. Carreño ${ }^{a}, *$, Irene T.S. Garcia ${ }^{a}$, Leidne S.S.M. Carreño ${ }^{a}$, Michael R. Nunes ${ }^{\mathrm{a}}$, \\ Edson R. Leite ${ }^{\mathrm{b}}$, Humberto V. Fajardo ${ }^{\mathrm{c}}$, Luiz F.D. Probst ${ }^{\mathrm{c}}$ \\ ${ }^{a}$ Instituto de Química e Geociência, DQAI, Universidade Federal de Pelotas, CP-354, CEP-96010-900, Capão do Leão, RS, Brazil \\ ${ }^{\mathrm{b}}$ LIEC/CMDMC-Departamento de Química, Universidade Federal de São Carlos, Via Washington Luiz, Km 235, CP-676, \\ CEP-13565-905, São Carlos, SP, Brazil \\ ${ }^{\mathrm{c}}$ Departamento de Química, Universidade Federal de Santa Catarina, CEP 88040-900 Florianópolis-SC, Brazil
}

Received 22 November 2006; received in revised form 9 July 2007; accepted 26 January 2008

\begin{abstract}
Here we describe a single chemical route to obtain highly dispersed nanometric Ni particles embedded in titania/carbon matrixes (amorphous and crystalline). The synthesis of these nanocomposites is based on a polymeric precursor method. The metallic Ni nanoparticles $(1-15 \mathrm{~nm})$ were obtained in a single process. We also present the results of photocatalytic experiments involving a series of nanocrystalline composites based on $\mathrm{TiO}_{2}$ /carbon with embedded Ni nanoparticles as nanocatalysts for rhodamine $6 \mathrm{G}$ degradation in aqueous solution and investigate the effects of the structure and properties of the nanocomposites on their photocatalytic applications. The effect of the different annealing treatments on the formation of $\mathrm{TiO}_{2}$ nanophases (anatase and/or rutile), the size of $\mathrm{Ni}$ particles and the role of the residual carbon phase on the final solid are also described.
\end{abstract}

(C) 2008 Elsevier Ltd. All rights reserved.

\section{Introduction}

Several methods for the synthesis of the $\mathrm{Ni} / \mathrm{TiO}_{2}$ catalysts have been recently reported in the literature [1-3]. These experimental procedures offer techniques that can lead to a significant enhancement of properties that are relevant to technological applications. The crystalline forms of $\mathrm{TiO}_{2}$ (anatase, brookite and rutile) have been functionalized with $\mathrm{Ni}$ metal particles. The different interfacial interactions of this transition metal on titania supports can be directly affected by the chemical route and precursor material used in the preparation of $\mathrm{Ni} / \mathrm{TiO}_{2}$ catalysts [4]. The properties of materials based on a modified titania matrix have been extensively studied, the main interest being in their unique electrochemical, optical, catalytic, semi-conducting and redox properties [2-4].

\footnotetext{
${ }^{*}$ Corresponding author.

E-mail address: neftali@ufpel.edu.br (N.L.V. Carreño).
}

Additionally, due to their low toxicity, appropriate energy band configurations for charge transfer at the interface, and absorption in the near UV range, titania-based catalysts are widely used in photocatalysis [4]. These catalysts, which offer great potential in environmental decontamination, particularly in the degradation of volatile organic compounds (VOC) [3,4], are often synthesized by sol-gel processes [5-7]. The size distribution, shape, and structure of supported metal nanoparticles influence the catalytic properties in ways that are still incompletely understood $[2,3,8,9]$. For example, Visinescu et al. [10] found that the photocatalytic activity of thin titania films was strongly influenced by the amount and the deposition conditions of the nickel. Li et al. [1] observed evidence for preferential nucleation and growth of $\mathrm{Ni}$ particles on titania supports (anatase and/or rutile) and demonstrated the importance of a precise control of the size and morphology of the nanoparticles in order the optimize the catalytic properties [1].

In this paper we report the modification of the method developed by Leite et al. [11] to synthesize nanocomposites 
based on a $\mathrm{TiO}_{2}$ matrix with embedded Ni nanoparticles. This new, in situ, bottom-up chemical process was recently used in the synthesis of nanometric Ni particles embedded in a mesoporous silica/carbon matrix [11-12]. This direct process for obtaining several nanocomposites consists of the formation of hybrid polymers composed of $\mathrm{C}, \mathrm{H}, \mathrm{O}$ and metal cations arrested within the macromolecule chain, followed by a controlled pyrolysis step. The $\mathrm{CO} / \mathrm{CO}_{2}$ atmosphere formed during this step promoted the reduction of the metal salt. The study of the catalytic [12] and magnetic [13] performance of this material has revealed interesting properties strongly dependent on the metal-metal and matrix-metal interactions, and on the nanoparticle size. However, the relationships between the processing conditions, structure and properties are not well understood. This information would allow the prediction and tailoring of the nanocomposite properties of new systems, such as titania/carbon doped with transition metal nanoparticles. In this regard, the present study aimed to obtain photocatalytic nanocomposites with different compositions as catalysts for the photochemical degradation of rhodamine $6 \mathrm{G}$. Rhodamine $6 \mathrm{G}$ is used as a test pollutant molecule, since it is known to create serious problems in the environment [14]. The role of transition metal nanoparticles embedded in the titania/carbon matrix in the thermal stability and morphology of the catalysts as well as on the process of the photocatalytic degradation of dyes is shown. The effect of the different annealing treatments on the formation of anatase and/or rutile nanophases, the particle size of $\mathrm{Ni}$ and the $\mathrm{TiO}_{2}$ derivatives, and the role of the residual carbon phase (carbonaceous material) is described.

\section{Experimental procedure}

The chemical process used for the preparation of the samples consists of the formation of a Ti-citrate complex (containing the $\mathrm{Ni}$-salt), followed by a polymerization step with ethylene glycol (EG), as can be seen in the flowchart of Fig. 1. The preparation and characterization of the intermediate titanium citrate has been described by Zampieri et al. [7] and Kakihana et al. [15]. The reported results show the role of the synthesis method on the ceramic materials obtained.

In this study, we prepared the nanocomposites by dissolving citric acid (Aldrich) in a mixture of water and titanium isopropoxide (Aldrich). Nickel nitrate (Ni $\left(\mathrm{NO}_{3}\right)_{2} \cdot 6 \mathrm{H}_{2} \mathrm{O}$; Aldrich) was then added and the mixture was homogenized for $15 \mathrm{~min}$ at room temperature.

A citric acid/metal ratio of 3:1 (in mol) was used. The metal concentration is the sum of $\mathrm{Ti}$ and $\mathrm{Ni}$, thus, $\mathrm{Ti}: \mathrm{Ni}$ ratios of 5:1 and 5:2 (mol) were prepared. The polymerization was initiated by adding EG to the metal/citrate solution, at a mass ratio of 40:60 in relation to the citric acid [1]. The $\mathrm{Ni}$ content of the final composites was determined by atomic absorption spectroscopy using a Hitachi-Z8230 instrument.

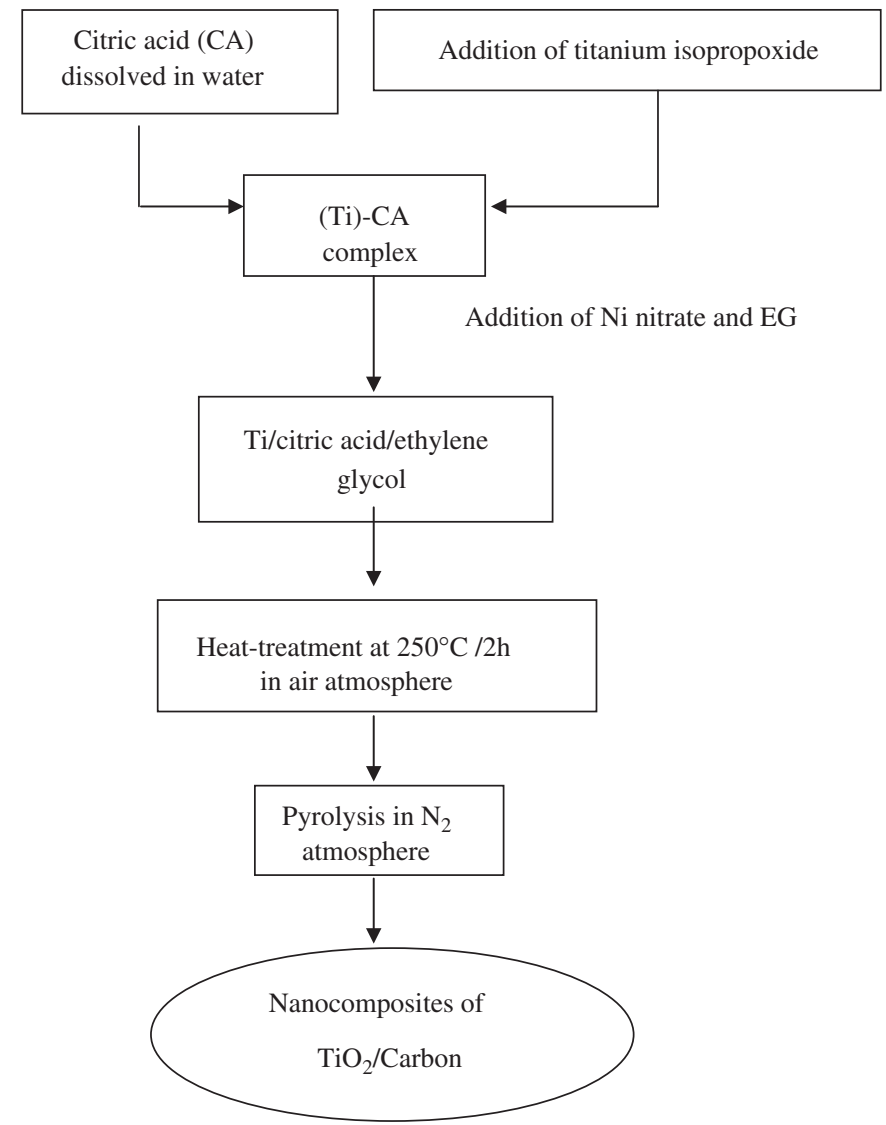

Fig. 1. Flowchart of route for obtaining $\mathrm{Ni}-\mathrm{TiO}_{2} /$ carbon nanocomposites.

The nanocomposites were obtained by a two-step pyrolysis of the polymeric intermediate. The first step $\left(2 \mathrm{~h}\right.$ at $250^{\circ} \mathrm{C}$, in air) promoted the breakage of the organic part of the polymeric intermediate. After this step, the material was milled in a ball mill, yielding a fine powder. This fine powder was submitted to a second heat treatment, performed in a $\mathrm{N}_{2}$ atmosphere, at temperatures higher than $400{ }^{\circ} \mathrm{C}$, during which the nanocomposites were formed. The temperatures used were selected on the basis of previous thermogravimetric (TG) analysis. A conventional $\mathrm{TiO}_{2}$ sample catalyst was also prepared for a comparative photocatalytic study with the nanocomposite samples. A single process of titanium isopropoxide (Adrich) pyrolysis at $400{ }^{\circ} \mathrm{C}$, for $6 \mathrm{~h}$ in an $\mathrm{O}_{2}$ atmosphere, was used to obtain the conventional $\mathrm{TiO}_{2}$ sample catalyst. The quantitative analysis of the carbon content in the conventional $\mathrm{TiO}_{2}$ sample was monitored by elemental analysis, using a FISONS EA $1108 \mathrm{CHN}$ analyzer, and carbon contamination was not observed.

The pyrolysis step was followed by TG analysis (model 409 Netzsch, Selb, Germany), using a $5{ }^{\circ} \mathrm{C} / \mathrm{min}$ heating rate under a $\mathrm{N}_{2}$ flow of $20 \mathrm{~cm}^{3} / \mathrm{min}$ and $10 \mathrm{mg}$ of sample. The nanocomposite powders were characterized by elemental analysis to determine the total coke content after the catalytic test. The crystal structure of the nanocomposites was characterized by XRD (Model D-5000, Siemens, 
Karlsruhe, Germany), using $\mathrm{CuK} \alpha$ radiation with a graphite monochromator.

X-ray photoelectron spectroscopy (XPS) analysis was performed using a commercial VG ESCA 3000 system operating at a pressure of 10-10 mbar. The spectra were collected using $\mathrm{MgK} \alpha$ radiation with an overall resolution of approximately $0.8 \mathrm{eV}$. The concentrations of the surface elements were calculated using the system database after subtracting the background counts. The $\mathrm{C} 1 \mathrm{~s}$ peak was used as the standard for the calibration of the binding energies.

The microstructure of the composites was investigated by scanning electron microscopy (SEM) using a SEM, DSM 940A microscope (Zeiss, Germany) and by transmission electron microscopy (TEM) using a Philips CM200 microscope operated at an acceleration voltage of $200 \mathrm{kV}$. For the TEM analysis, a drop of the suspended composite was deposited on a carbon-covered copper grid.

Specific surface area and pore volume of the nanocomposites were determined by $\mathrm{N}_{2}$ adsorption/desorption isotherms, at liquid nitrogen temperature, using an Autosorb-1C analyzer (Quantachrome Instruments). The metallic $\mathrm{Ni}$ surface on the titania support was also investigated through chemisorption analysis. The prior $\mathrm{H}_{2}$ activation of the individual samples was necessary for this specific chemisorption test. A powder sample (40-50 mg, reduced at $400{ }^{\circ} \mathrm{C}$ in $\mathrm{H}_{2}$ flow) was outgassed at $300^{\circ} \mathrm{C}$ for $2 \mathrm{~h}$ before the metal area measurements. Despite that XRD analysis for the $\mathrm{Ni} / \mathrm{TiO}_{2}$ nanocomposites was carried out immediately after the pyrolysis step of the polymeric a peak corresponding to the Ni metal phase is present. However, it is possible that there is an ultra-thin oxide layer present on the Ni metal particles, inhibiting the clear identification of externally exposed active sites on surface of $\mathrm{TiO}_{2} /$ carbon matrix. Thus, the $\mathrm{H}_{2}$ chemisorption of the catalysts was performed at $27^{\circ} \mathrm{C}$ after the reduction of the sample $(0.5 \mathrm{~g})$ in a flow of $\mathrm{H}_{2}\left(30 \mathrm{~cm}^{3} / \mathrm{min}\right)$ at $400{ }^{\circ} \mathrm{C}$ $\left(10^{\circ} \mathrm{C} / \mathrm{min}\right)$ for $1 \mathrm{~h}$ and evacuation for $1 \mathrm{~h}$ at the same temperature monitored using Quantachrome instruments.

For some of the photocatalytic experiments a UV lamp (based on mercury) was used as a light source to degrade the rhodamine $\mathrm{G}\left(1 \times 10^{-5} \mathrm{M}\right.$; Aldrich $)$ in the presence of the synthesized nanocomposites as catalysts and the degradation of the rhodamine was monitored with a Varian (5G) UV-spectrometer. We used similar procedures to determine the photocatalytic activity of conventional, crystalline $\mathrm{TiO}_{2}$ (with both anatase and rutile phases). In order to check the reproducibility of the photocatalytic behavior each sample was tested in several runs.

\section{Results and discussion}

\subsection{Nanocomposite formation}

Fig. 2 shows the TG analysis of the intermediate polymers with different $\mathrm{Ni}$ contents $(0,6.6$ and $12.0 \mathrm{wt} \%)$. For all samples a well-defined weight loss at around $200^{\circ} \mathrm{C}$ was observed, which is associated with the breakage of the organic part of the hybrid polymeric intermediate. Additional weight losses were observed above 350 and above $500{ }^{\circ} \mathrm{C}$ for $\mathrm{TiO}_{2}$ and $\mathrm{Ni}-\mathrm{TiO}_{2} /$ carbon samples as illustrated in Fig. $2 \mathrm{~b}$ for the $\mathrm{Ni}-\mathrm{TiO}_{2}$ $(\sim 12.0 \mathrm{wt} \% \mathrm{Ni})$ sample. This sample showed a weight loss of $37.1 \%$ between 350 and $400{ }^{\circ} \mathrm{C}$ and a weight loss of $8.0 \%$ between 500 and $900{ }^{\circ} \mathrm{C}$. The weight loss between 350 and $400{ }^{\circ} \mathrm{C}$ was attributed to the formation of a carbonaceous material phase.

As mentioned above, based on these thermogravimetric results the pyrolysis of the polymeric intermediate was carried out in two steps; one at $250^{\circ} \mathrm{C}$ in air to break the organic part of the polymer and a second at temperatures higher than $400^{\circ} \mathrm{C}$ in nitrogen atmosphere for the formation of a nanocomposite $\left(\mathrm{TiO}_{2} /\right.$ carbon $)$ phase. This two-step pyrolysis results in the formation of a carbonaceous material, as corroborated by elemental analysis ( $\mathrm{CHN}$ analysis), which revealed that after the second heattreatment step the carbon content varied between $29-38 \mathrm{wt} \%$ as a function of the annealing treatment and the $\mathrm{Ni}$ metal content. The presence of a significant amount

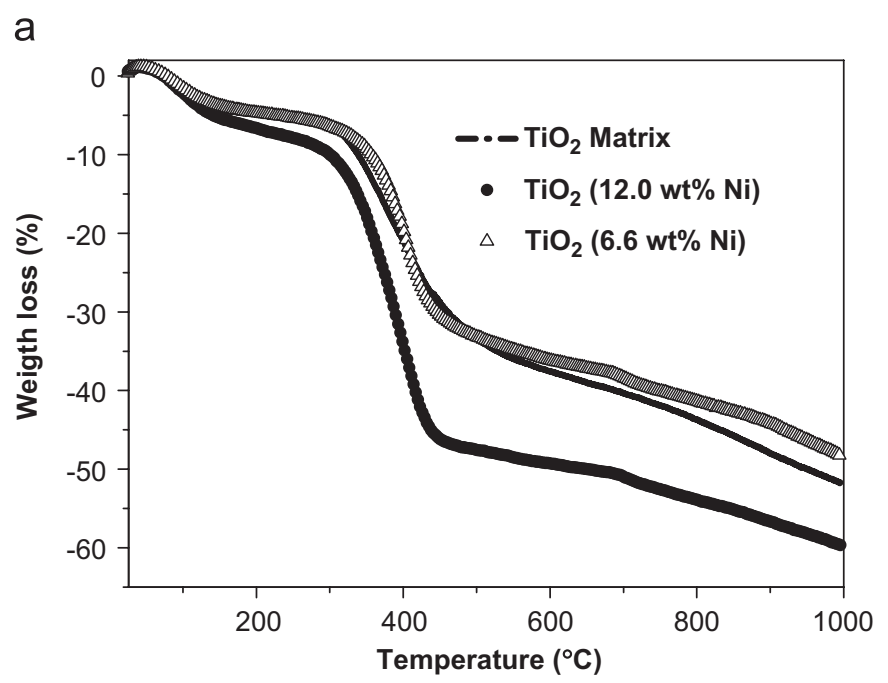

b

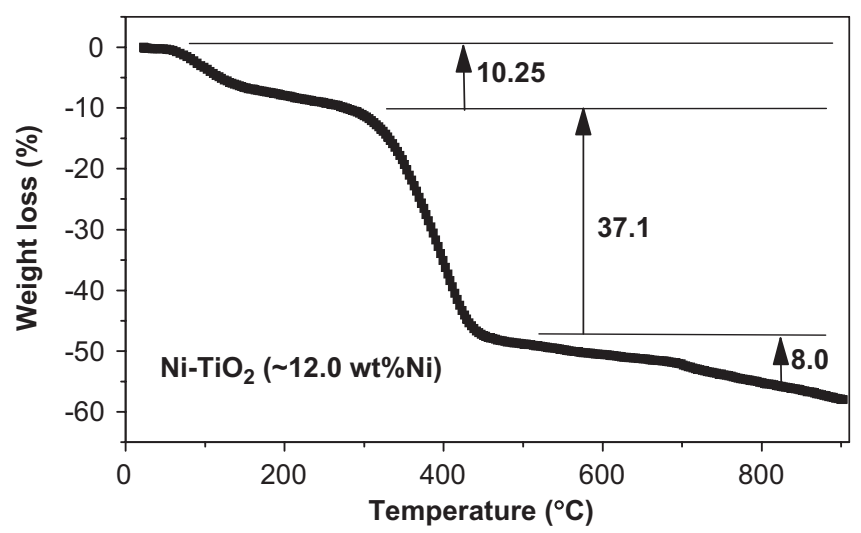

Fig. 2. TG analysis of the precursors: (a) all systems; (b) $\mathrm{Ni}-\mathrm{TiO}_{2} /$ carbon $(12.0 \mathrm{wt} \% \mathrm{Ni})$, sample mass of $10 \mathrm{mg} ; \mathrm{N}_{2}$ flow of $20 \mathrm{~cm}^{3} / \mathrm{min}$. 
of carbon residues during the annealing contributes to changes in the surface of $\mathrm{Ni}-\mathrm{TiO}_{2} /$ carbon systems.

During the pyrolysis the breaking of the organic macromolecule generates a $\mathrm{CO} / \mathrm{CO}_{2}$-rich atmosphere which promotes the reduction of the $\mathrm{Ni}$ salt and the formation of metal nanoparticles in a polymorph matrix (crystalline and amorphous) formed basically of $\mathrm{TiO}_{2}$ and residual amorphous carbon. These $\mathrm{Ni}$ particles are preferentially embedded within the crystalline matrix and are not deposited on the matrix surface $[9,11,12]$.

The crystal structure of the nanocomposites and the respective patterns are presented in Fig. 3a-c. The patterns of the Ni-containing composites (Fig. $3 \mathrm{~b}$ and c) indicate the presence of metallic nickel, thus confirming the reduction of the $\mathrm{Ni}$ salts by the $\mathrm{CO} / \mathrm{CO}_{2}$ atmosphere generated during the pyrolysis of the polymeric precursor material. The X-ray diffraction pattern of the $\mathrm{TiO}_{2} /$ carbon nanocomposite, as a function of the annealing temperature, is shown in Fig. 3a. In this pattern the peaks can be ascribed to the tetragonal anatase phase of crystalline $\mathrm{TiO}_{2}$. The tetragonal rutile phase was not formed during the annealing of the $\mathrm{TiO}_{2} /$ carbon and $\mathrm{Ni}-\mathrm{TiO}_{2} /$ carbon $(\sim 12.0 \mathrm{wt} \% \mathrm{Ni})$ matrixes at temperatures up to 600 and $700{ }^{\circ} \mathrm{C}$. However, for the $\mathrm{Ni}-\mathrm{TiO}_{2}(\sim 6.6 \mathrm{wt} \% \mathrm{Ni})$ sample, the formation of rutile was observed at an annealing temperature of $800^{\circ} \mathrm{C}$ (Fig. 3b), and was also observed for pure titania, where the anatase to rutile transformation takes place at around $780^{\circ} \mathrm{C}$ [16]. The XRD patterns of all composites (Fig. 3a-c) also show that the amount of amorphous phase decreases with an increase of the annealing temperature.

Fig. 3d shows the scanning electron micrograph of the $\mathrm{Ni}-\mathrm{TiO}_{2} /$ carbon $(\sim 6.6 \mathrm{wt} \% \mathrm{Ni})$ sample annealed at $500^{\circ} \mathrm{C}$, which shows the typical ribbon-shaped morphology of the nanocomposite particles, which was also observed for the $\mathrm{Ni}-\mathrm{TiO}_{2}(\sim 12.0 \mathrm{wt} \% \mathrm{Ni})$ sample (not shown).

Fig. 4 a demonstrates the particle size distribution of the $\mathrm{Ni}-\mathrm{TiO}_{2}(\sim 6.6 \mathrm{wt} \% \mathrm{Ni})$ sample determined from its bright field-TEM image shown in Fig. 4b. In this micrograph the Ni nanoparticles are observed as dark spots well dispersed within the $\mathrm{TiO}_{2} /$ carbon matrix, with a mean particle size of $8.6 \mathrm{~nm}$ (Fig. 4a). The regular arrangement of the $\mathrm{Ni}$ nanoparticles embedded within the $\mathrm{TiO}_{2} /$ carbon matrix suggests a high dispersion, as confirmed by the highest values determined for the metallic dispersion on the surface of the $\mathrm{Ni}-\mathrm{TiO}_{2}(\sim 6.6 \mathrm{wt} \% \mathrm{Ni})$ sample, given in Table 1 . These observations are in agreement with the results of previous studies reported by Rouiller and Assaf [17] and Navarro et al. [18]. Fig. 4c shows the high resolution transmission electron micrograph of the $\mathrm{Ni}: \mathrm{TiO}_{2} /$ carbon $(6.6 \mathrm{wt} \% \mathrm{Ni})$ nanocomposite, which confirms the presence of $\mathrm{TiO}_{2}$ (anatase) nanocrystals with particle sizes a

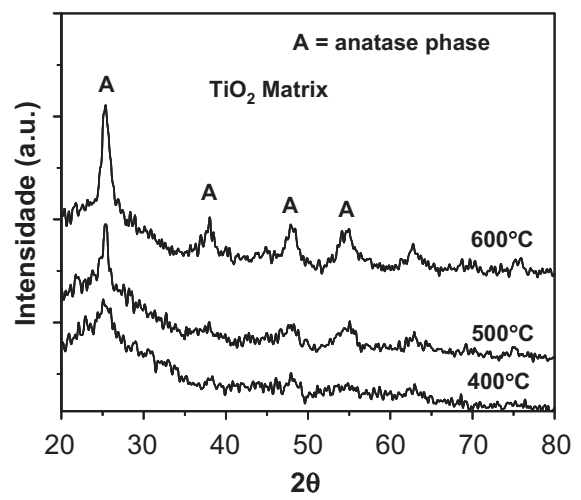

b

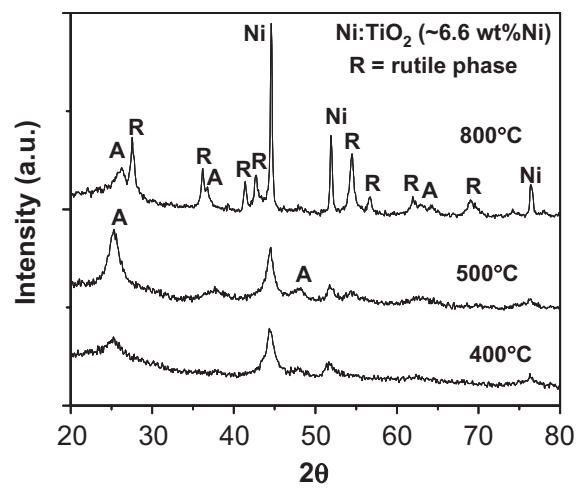

C

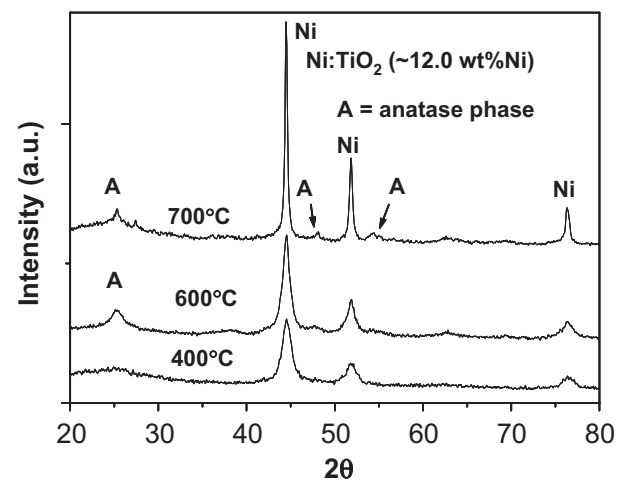

d

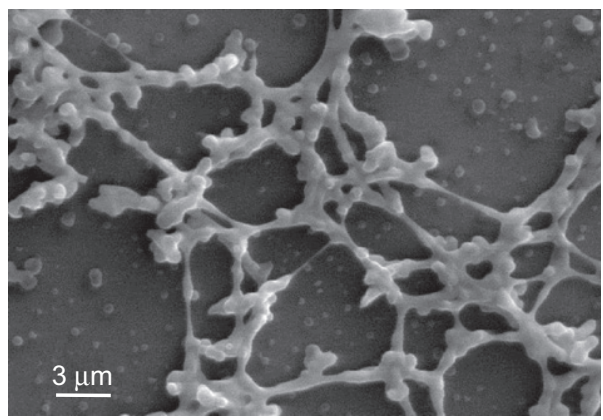

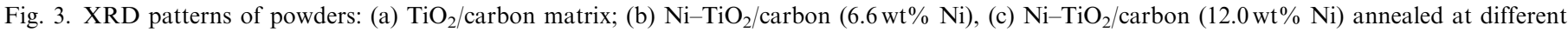

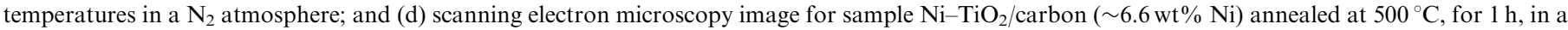
$\mathrm{N}_{2}$ atmosphere. 
a

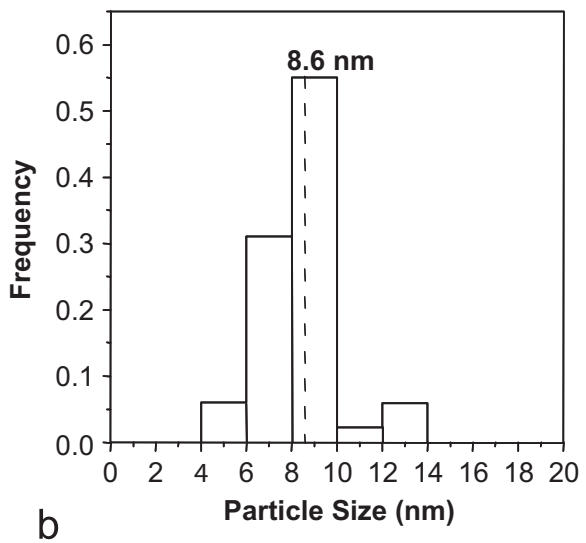

C
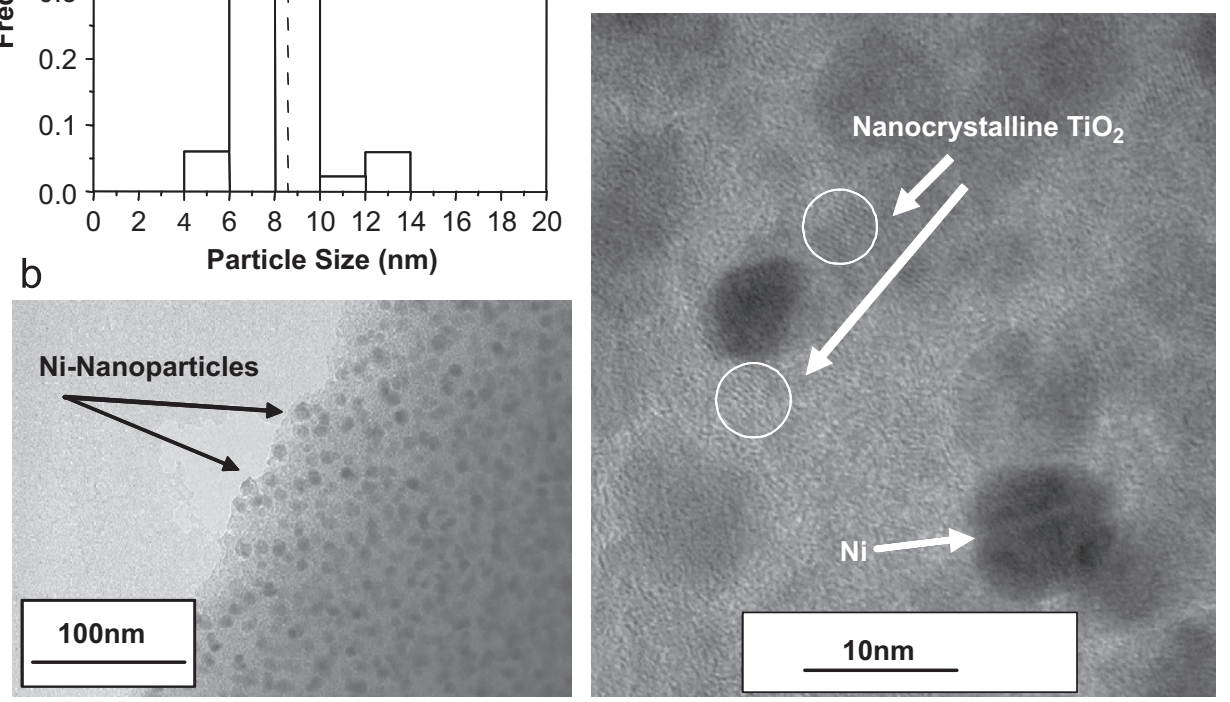

Fig. 4. The $\mathrm{Ni}: \mathrm{TiO}_{2} /$ carbon $\left(\sim 6.6 \mathrm{wt} \% \mathrm{Ni}\right.$ ), annealed at $400{ }^{\circ} \mathrm{C}$ for $1 \mathrm{~h}$, in a $\mathrm{N}_{2}$ atmosphere: (a) mean particle size and frequency; (b) bright fieldtransmission electron Microscopy image; and (c) high-resolution transmission electron microscopy (HRTEM) image.

Table 1

Crystallite size (average diameter-X-ray), particle size (TEM), BET specific surface area, average pore diameter and metallic dispersion of the Ni nanoparticles, for nanocomposites at different pyrolysis temperatures

\begin{tabular}{lllllrr}
\hline$X \%$ - Sample & $\begin{array}{l}\text { Pyrolysis } \\
\text { temperature }\left({ }^{\circ} \mathrm{C}\right)\end{array}$ & $\begin{array}{l}\text { BET surface } \\
\text { area }\left(\mathrm{m}^{2} \mathrm{~g}\right)\end{array}$ & $P_{\mathrm{D}}(\AA)$ & $D_{\beta}(\mathrm{nm})$ & $\begin{array}{l}D_{\text {TEM }}(\mathrm{nm}) \\
(\%)\end{array}$ \\
\hline $6.6 \%-\mathrm{Ni}: \mathrm{TiO}_{2}$ & 400 & 10 & 148 & 7.7 & 8.6 & 47 \\
$12 \%-\mathrm{Ni}: \mathrm{TiO}_{2}$ & 400 & 2 & 139 & 7.8 & 9.0 & 17 \\
$12 \%-\mathrm{Ni}: \mathrm{TiO}_{2}$ & 500 & 3 & 117 & 8.4 & -2 & - \\
\hline
\end{tabular}

$X \%=$ atomic percentage of $\mathrm{Ni}$, determined by atomic absorption.

$P_{\mathrm{D}}=$ average pore diameter.

$D_{\beta}=$ crystallite size determined from line-broadening measurements of the (1 111$)$ Ni peak, using the Scherrer Eq. (19).

$D_{\text {TEM }}=$ nanoparticle size determined by TEM.

below $2.0 \mathrm{~nm}$ in the circled area, as previously observed by XRD analysis, and allows the observation of the $\mathrm{Ni}$ particles (diameter around $8.6 \mathrm{~nm}$ ). Additional information on the textural properties of the nanocomposites (surface area, crystallite size, average pore diameter, particle size and metal dispersion) is summarized in Table 1. The crystallite size of the metal component of the nanocomposites in the titania matrix studied was determined using the Scherrer equation, using the (1 111$)$ diffraction peak [19]. In this study, the diffraction peak profile was fitted using a pseudo-Voigt function to calculate the full-width at halfmaximum (FWHM). The mean particle size was also estimated by TEM, examining different regions of the samples. The mean particle size values thus obtained are in good agreement with the crystallite sizes determined by
XRD (see Table 1). Furthermore, the result obtained for the $\mathrm{Ni}-\mathrm{TiO}_{2}(\sim 12.0 \mathrm{wt} \% \mathrm{Ni})$ sample may be associated with lower distributions and agglomeration of the $\mathrm{Ni}$ metallic sites on the surface of $\mathrm{TiO}_{2} /$ carbon matrix. Thus, the increase in Ni concentrations also promoted a slight increased in Ni particle size in this nanocomposite system. Fig. 5 shows the (a) HRTEM and (b) bright field-TEM image of $\mathrm{Ni}: \mathrm{TiO}_{2} /$ carbon $(\sim 12.0 \mathrm{wt} \% \mathrm{Ni})$, annealed at $500{ }^{\circ} \mathrm{C}$ for $1 \mathrm{~h}$, in a $\mathrm{N}_{2}$ atmosphere, and the particle size diameter is significantly greater than that observed for the $\mathrm{Ni}: \mathrm{TiO}_{2} /$ carbon $(\sim 6.6 \mathrm{wt} \% \mathrm{Ni})$ sample. The $\mathrm{Ni}: \mathrm{TiO}_{2} /$ carbon $(\sim 12.0 \mathrm{wt} \% \mathrm{Ni})$ powder also shows the presence of agglomerates constituted of Ni nano-sized particles.

To investigate the nanocomposite surface and the effect of the residual carbon on it, X-ray photoemission 

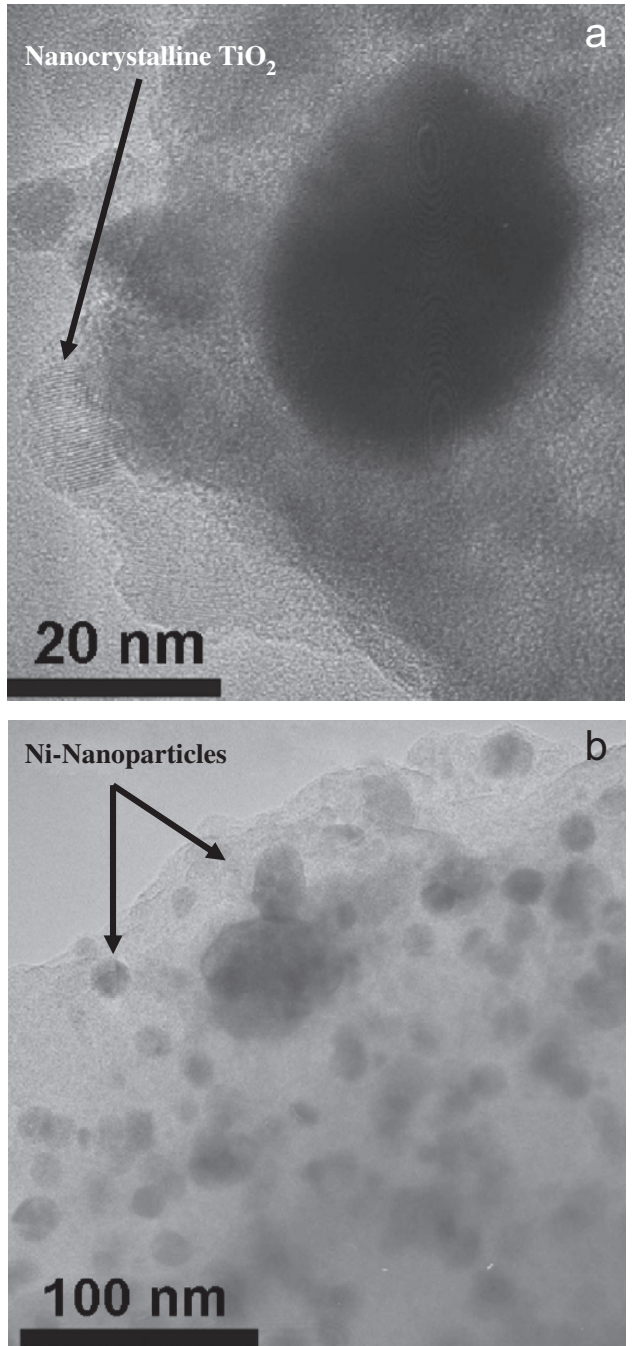

Fig. 5. The $\mathrm{Ni}: \mathrm{TiO}_{2} /$ carbon $(\sim 12.0 \mathrm{wt} \% \mathrm{Ni})$, annealed at $500{ }^{\circ} \mathrm{C}$ for $1 \mathrm{~h}$, in a $\mathrm{N}_{2}$ atmosphere: (a) high-resolution transmission electron microscopy (HRTEM) image; (b) bright field-transmission electron microscopy image.

experiments were carried out with the $\mathrm{Ni}-\mathrm{TiO}_{2} /$ carbon $(\sim 12.0 \mathrm{wt} \% \mathrm{Ni})$ sample, (Fig. 6). The weak, slightly broad, peak assigned to nickel $\mathrm{Ni} 2 \mathrm{p}_{3 / 2}$ binding energies of $\mathrm{Ni}^{2+}$ and $\mathrm{Ni}^{\circ}$, at around between 854 and $852 \mathrm{eV}$, can be observed in Fig. 6a [20]. The value for the Ni concentration (\%) on the surface of the samples (basically formed by carbonaceous material and $\mathrm{TiO}_{2}$ ) determined by XPS is much lower than that determined by metallic dispersion analysis (in Table 1). This suggests that the $\mathrm{Ni}$ nanoparticles are embedded in the $\mathrm{TiO}_{2} /$ carbon denser matrix. In addition, the XPS result for the $\mathrm{Ni}-\mathrm{TiO}_{2} /$ carbon $(\sim 12.0 \mathrm{wt} \% \mathrm{Ni})$ sample (Fig. 6a) can be compared to the nanocomposite formed of only Ni metal nanoparticles and a carbonaceous matrix ( $\sim 27.0 \mathrm{wt} \% \mathrm{Ni}$ in carbon, Fig. $6 \mathrm{~b})$. This sample was prepared by a similar chemical method, without the presence of the titanium citrate complex. Its XRD pattern (not shown) confirms the formation of a carbon-based material with an amorphous phase and $\mathrm{Ni}$ metal as the only crystalline phase. However, the XPS spectrum (Fig. 6b) does not show Ni at the surface of the
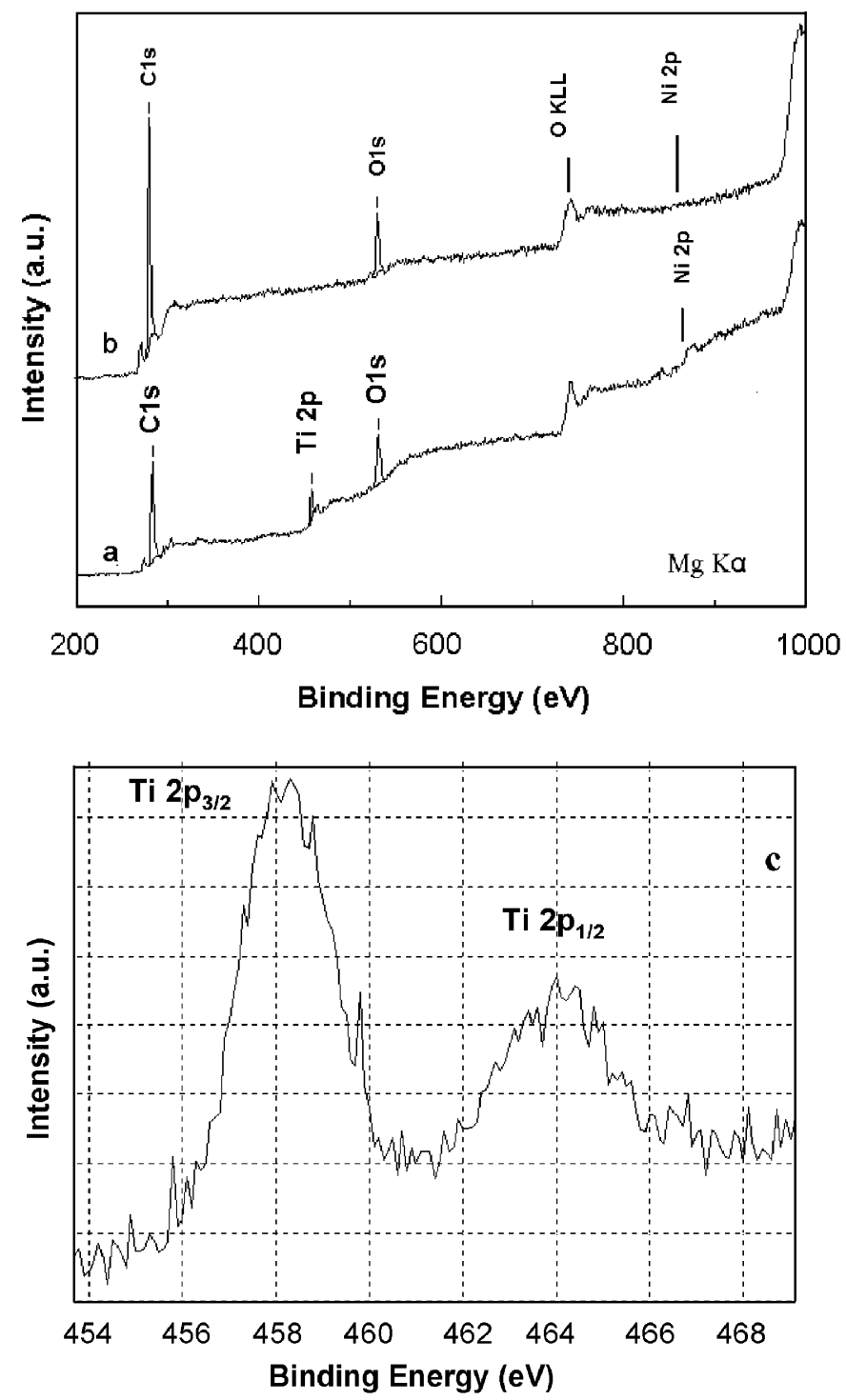

Fig. 6. XPS survey spectrum for (a) $\mathrm{Ni}-\mathrm{TiO}_{2} /$ carbon $(\sim 12.0 \mathrm{wt} \% \mathrm{Ni})$ (b) carbon matrix $(\sim 27.0 \mathrm{wt} \% \mathrm{Ni})$; (c) $\mathrm{Ni}-\mathrm{TiO}_{2} /$ carbon $(\sim 12.0 \mathrm{wt} \% \mathrm{Ni})$ nanocomposites annealed at $400{ }^{\circ} \mathrm{C}$ for $1 \mathrm{~h}$, in a $\mathrm{N}_{2}$ atmosphere.

carbon matrix, i.e., the $\mathrm{Ni} 2 \mathrm{p}_{3 / 2}$ peak is absent, indicating that practically all of the $\mathrm{Ni}$ is embedded in the carbon matrix. Analysis of the textural properties of the crystalline $\mathrm{Ni}$ nanoparticles embedded in the carbon matrix revealed the formation of a typical microporous material with a large specific surface area and high porosity [9], where the residual carbon works as a textural promoter, protecting the metal particles inside the porous matrix. This has been observed in a previous study on ceria derived catalysts for $\mathrm{CO}_{2}$ reforming of $\mathrm{CH}_{4}$ [9]. In contrast, the $\mathrm{Ni}$ particles of $\mathrm{Ni}-\mathrm{TiO}_{2} /$ carbon nanocomposites present were slightly exposed at the external surface of the matrix, as is indicated by the $\mathrm{Ni} 2 \mathrm{p}_{3 / 2}$ peak in Fig. 6a. These Ni particles are in a denser matrix with low specific surface area, however, the presence of significantly smaller average pore diameters may be associated with textural changes due to the presence of residual carbonaceous material. 
Nagaoka et al. [21] described the synthesis of precursors based on cellulose and $\mathrm{TiO}_{2}$ particles to obtain carbon/ $\mathrm{TiO}_{2}$ microspheres with different surface textures and chemical properties, which they assigned to the presence of carbon. According to these observations and our results, the low nickel concentration detected at the surface of $\mathrm{Ni}-\mathrm{TiO}_{2} /$ carbon composites, particularly in the case of the $\mathrm{Ni}$-carbon composite, is attributed to the chemical process, which allows us to obtain a homogenous $\mathrm{Ni}$ distribution in the polymeric intermediate. This intermediate is subsequently transformed into $\mathrm{Ni}$ nanoparticles embedded in the ceramic matrix, along with residual carbon, through the annealing treatment.

Figs. $6 \mathrm{a}$ and $\mathrm{c}$ show the binding energies of the Ti $2 \mathrm{p}$ photoelectron peaks at 458.5 and $464.4 \mathrm{eV}$ which correspond to the Ti $2 p_{3 / 2}$ and $2 p_{1 / 2}$ peaks, respectively [23]. The $\operatorname{Ti} 2 \mathrm{p}_{3 / 2}$ binding energy indicates that $\mathrm{Ti}$ exists in a $4+$ oxidation state, as is expected for $\mathrm{TiO}_{2}$ (anatase), the presence of which was observed by XRD and HRTEM.

\subsection{Photocatalytic study of nanocomposites}

In order to investigate the effect of $\mathrm{Ni}^{\circ}$ nanoparticles embedded in the nanocrystalline matrix, their photocatalytic properties in the photodegradation of rhodamine $6 \mathrm{G}$ were investigated. Fig. 7 shows the results of this photocatalytic degradation, which was carried out in aqueous solution to evaluate the efficiency of the photodecomposition of organic pollutants by different $\mathrm{Ni}-\mathrm{TiO}_{2} /$ carbon catalyst system, annealed at $400{ }^{\circ} \mathrm{C}$. The results indicate that the efficiency of the photodecomposition increased strongly when the nanocrystalline $\mathrm{TiO}_{2}$ matrix (prepared by polymeric precursor method) was used instead of a conventional $\mathrm{TiO}_{2}$ catalyst. Also, the $\mathrm{Ni}$

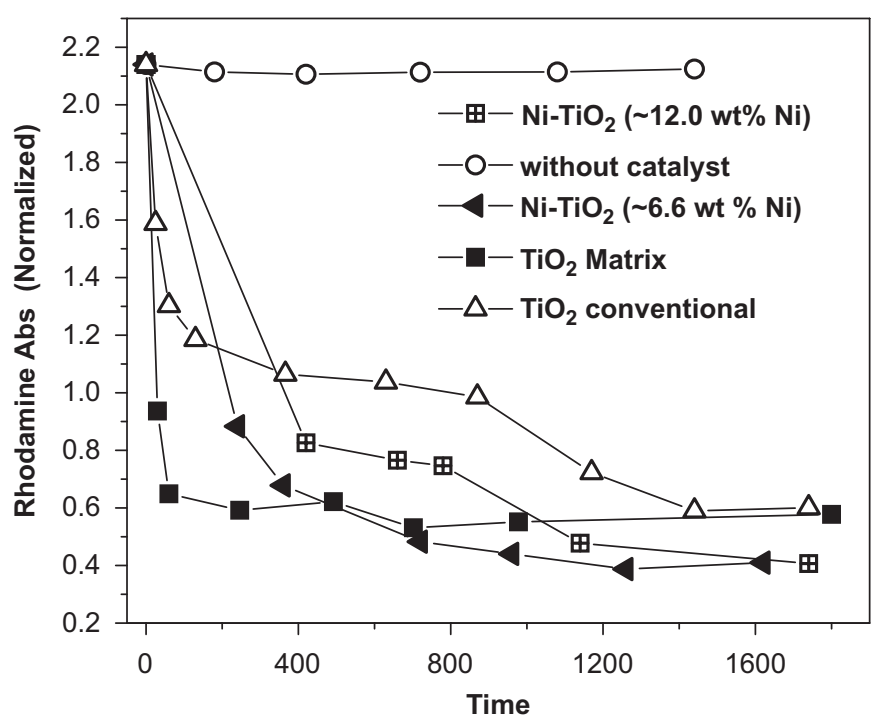

Fig. 7. Rhodamine $6 \mathrm{G}$ remaining in solution after photocatalytic test (absorption) as a function of illumination time, application of several nanocomposites, annealed at $400{ }^{\circ} \mathrm{C}$ for $1 \mathrm{~h}$, in a $\mathrm{N}_{2}$ atmosphere, and conventional $\mathrm{TiO}_{2}$ sample catalyst. embedded in the nanocomposites prepared by synthesis based on a polymeric precursor, demonstrates a very significant improvement of their activity. However, the observed initial degradation rate and efficiency of the $\mathrm{TiO}_{2}$ polymorph matrix (nanocrystalline anatase) was higher than that observed for $\mathrm{Ni}-\mathrm{TiO}_{2}$ nanocomposites. Therefore, the presence of $\mathrm{Ni}$ leads to a decrease in the photocatalytic activity of the $\mathrm{TiO}_{2}$ nanocomposites. However, the $\mathrm{Ni}-\mathrm{TiO}_{2} /$ carbon nanocomposites, show a more significant effect on the degradation rate than conventional $\mathrm{TiO}_{2}$. This higher photocatalytic efficiency of $\mathrm{TiO}_{2} /$ carbon matrixes synthesized by a chemical process, which contain residual carbon, support our results regarding the role of residual carbon at the surface of the nanocomposites in concentrating the target molecules of the photocatalytic process, at the $\mathrm{TiO}_{2}$ surface $[23,24]$. Thus, the degradation of organic molecules, like Rhodamine $6 \mathrm{G}$, seems to be due to their surface diffusion to the active centers on the surface of the $\mathrm{TiO}_{2}$ photocatalyst, which is mainly influenced by the residual porous carbon at the surface. In addition, the nickel nanoparticles (transition metal) may improve the trapping of electrons, inhibiting electron-hole recombination during the photocatalytic process $[2,10,21]$, through the rapid transfer of the photogenerated electrons from $\mathrm{TiO}_{2}$ to the metal nanoparticles, resulting in a modified separation of the electrons and holes [14,22]. Visinescu et al. [10] found that in the photocatalytic decomposition of acetone by Ni-doped thin film titania catalysts, the presence of Ni has a strong influence on the photocatalytic properties, and that there is a limited $\mathrm{Ni}$ concentration range for the enhancement of the activity of titania catalysts. Several authors suggest that the role of the doping ions and transition metal in the modification of the titania photocatalytic properties is not completely understood and recommend further investigations [2,10,25]. Additional carbonaceous deposits on alumina, when used as supports for platinum, resulted in very selective catalysts [26]. The modification of semiconductors involving transition metals and ions has become an attractive approach to finding other properties such as catalytic selectivity and gas sensing.

\section{Conclusions}

The results here presented demonstrate the possibility to obtain $\mathrm{Ni}$ metal nanoparticles embedded within $\mathrm{TiO}_{2} /$ carbon nanocomposites, using a sol-gel synthesis route. This microstructural feature, Ni nanoparticles embedded within a crystalline, amorphous or polymorphic matrix powder, also constituted of nano-size crystallite $\mathrm{TiO}_{2}$, obtained by a single annealing treatment, can result in new materials with interesting catalytic applications. Additionally, the presence of residual amorphous carbon influences the nature of the matrix support and surface properties. Thus, there is considerable interest in preparing nanocomposite materials with completely controlled architectures that can be tailored for specific technical 
applications, such as photocatalysis, and host other metallic particles.

\section{Acknowledgments}

The authors acknowledge the following Brazilian funding support agencies: CNPq, FINEP/CT-PETRO and FAPERGS/PROADE.

\section{References}

[1] P. Li, J. Liu, N. Nag, P.A. Crozier, Surf. Sci. 600 (2006) 693-702.

[2] C.C. Cheng, X.Z. Li, W.H. Ma, J.C. Zhao, H. Hidaka, N. Serpone, J. Phys. Chem. B 106 (2002) 318-324.

[3] M. Asilturk, F. Sayılkan, S. Erdemoglu, M. Akarsu, H. Sayılkan, M. Erdemoglu, E. Arpac, J. Hazardous Mater. B 129 (2006) 164-170.

[4] S.W. Ho, C.Y. Chu, S.G. Chen, J. Catal. 178 (1998) 34.

[5] E.R. Leite, N.L.V. Carreño, L.P.S. Santos, J.H. Rangel, L.E.B. Soledade, E. Longo, C.E.M. Campos, F. Lanciotti, P.S. Pizani, J.A. Varela, Appl. Phys. A 73 (2001) 567-569.

[6] T. Sreethawong, Y. Suzuki, S. Yoshikawa, Int. J. Hydrogen Energy 30 (2005) 1053-1062.

[7] M. Zampieri, S.R. Lazaro, C.A. Paskocimas, A.G. Ferreira, E. Longo, J.A. Varela, J. Sol-Gel Sci. Tech. 37 (2006) 9-17.

[8] N.L.V. Carreño, E.R. Leite, E. Longo, P.N. Lisboa-Filho, A. Valentini, L.F.D. Probst, W.H. Schreiner, J. Nanosci. Nanotech. 2 (2002) 491-494.

[9] A. Valentini, N.L.V. Carreño, L.F.D. Probst, A. Barison, A.G. Ferreira, E.R. Leite, E. Longo, Appl. Catal. A. Gen. 310 (2006) 174-182.

[10] C.M. Visinescu, R. Sanjines, F. Levy, V.I. Parvulescu, Appl. Catal. B: Environ. 60 (2005) 155-162.
[11] E.R. Leite, N.L.V. Carreño, E. Longo, F.M. Pontes, A. Barison, A.G. Ferreira, Y. Maniette, J.A. Varela, Chem. Mater. 14 (2002) 3722-3729.

[12] N.L.V. Carreño, E.R. Leite, E. Longo, P.N. Lisboa-Filho, A. Valentini, L.F.D. Probst, W.H. Schreiner, J. Nanosci. Nanotech. 2 (2002) 491-494.

[13] F.C. Fonseca, G.F. Goya, R.F. Jardim, R. Mucillo, N.L.V. Carreño, E. Longo, E.R. Leite, Phys. Rev. B 66 (2002) 104406-104411.

[14] Y. Miyajima, S. Mizoguchi, A. Nakamura, Y. Kuroiwa, Y.Y. Kato, T. Watanabe, Chem. Lett. 35 (2006) 1034-1035.

[15] M. Kakihana, M. Arima, Y. Nakamura, M. Yashima, M. Yoshimura, Chem. Mater. 11 (1999) 438-450.

[16] J. Yang, Y.X. Huang, J.M.F. Ferreira, J. Mater. Sci. Lett. 16 (1997) 1935-1937.

[17] C.O. Rouiller, J.M. Assaf, Chem. Eng. Sci. 51 (1996) 2921-2925.

[18] R.M. Navarro, M.C. Alvarez-Galvan, F. Rosa, J.L.G. Fierro, Appl. Catal. A. Gen. 297 (2006) 60-72.

[19] N.L.V. Carreno, E.R. Leite, L.PS. Santos, P.N. Lisboa, E. Longo, G.C.L. Araujo, A. Barison, A.G. Ferreira, A. Valentini, L.F.D. Probst, QUIMICA NOVA 25 (2002) 935-942.

[20] K. Takanabe, K. Nagaoka, K. Nariai, K. Aika, J. Catal. 232 (2005) 268-275.

[21] S. Nagaoka, Y. Hamasaki, S. Ishihara, M. Nagata, K. Iio, C. Nagasawa, H. Ihara, J. Mol. Catal. A Chem. 177 (2002) 255-263.

[22] C. Minero, F. Catozzo, E. Pelizzetti, Langmuir 8 (1992) 481-486.

[23] B.M. Reddy, K.N. Rao, G.K. Reddy, P. Bharah, J. Mol. Catal. 253 (2006) 44-51.

[24] K. Hirano, H. Asayama, A. Hiroshino, H. Wakatsuki, J. Photochem. Photobiol. A 110 (1997) 307.

[25] C. Minero, G. Marirlla, V. Maurino, E. Pelizzetti, Langmuir 16 (2000) 2632-2641.

[26] R. Fiedorow, R. Franski, A. Krawczyk, S. Beszterda, J. Phys. Chem. Sol. 65 (2004) 627-632 